\title{
Participatory and evidence-informed general practice
}

Evidence-informed health care requires clinicians to combine their clinical experience with research evidence, in addition to the values of their patients. ${ }^{1,2}$ There is a complementary argument for participatory approaches that integrate clinical experience and patient values within evidence-informed clinical guidelines and standards of care. This melding of patients' values and evidence is challenging for two reasons. The first challenge is how to integrate, rather than choose between, these different forms of knowledge when making decisions about how services should operate. The second challenge is how to involve many clinicians and many service users in decisions with wide-reaching consequences. Making decisions collectively about priorities and standards raises questions about whom to involve and how, and about the evidence to inform these decisions.

Public participation at a collective level has often been initiated by the public. In 1960s Britain, parents campaigned for better hospital services for children. Since then, pregnant women and young families have campaigned for improvements in British maternity services. Breast cancer, HIV/AIDS, and mental health survivors have campaigned internationally for better care and more relevant research.

Now public participation is often initiated by research and service organisations who wish to involve patients more broadly, not only those aligned with campaigning organisations. Public involvement meets evidence-informed health care in prioritising issues for research, in conducting research, in developing evidence-informed guidelines and standards of care, and in monitoring that care.

There is strong policy support for public involvement in research. INVOLVE is the national advisory group, funded through the National Institute for Health Research, that aims to improve the way that research is prioritised, commissioned, undertaken, communicated, and used (www.invo.org.uk). Active involvement of patients, other service users, and the public in the research process is expected to lead to research which reflects their needs and views, and subsequently more likely to produce results that can be used to improve practice in health and social care. There are roles for patients and the public too in transferring the research findings into policy, practice, and personal decisions. Patients may consider the evidence when sharing decisions with a clinician for their care as an individual; or they may take part in developing or implementing guidelines for practice more generally. ${ }^{3}$

Clarity about the purpose of public involvement and what is to be achieved is a prerequisite for choosing methods for involvement, the timing, and potential participants. There are ethical arguments about rights and citizenship that justify involvement in choosing areas of life most deserving of attention. These arguments support involvement of the wider public as citizens and tax payers in prioritising problems and ensuring accountability of organisations. An innovative example is the NICE Citizens Council's debate of priorities in terms of clinical need, age, or health inequalities. ${ }^{4}$

There are also pragmatic arguments about the relevance of research and services, the use of research findings, and the potential impact on health, that justify involvement in deciding how research should be conducted and services developed. These arguments support involvement of specific service users, with their specific expertise, in finding solutions. Whether the arguments are ethical or pragmatic, inviting involvement can only be justified when patient or public expertise is required and can make a difference: when there is the potential for involvement to either change decisions, or change the level of confidence in decisions.

Involvement may be passive, through a representative sample of individuals providing data for research, evaluation, or audit. Alternatively, more active involvement allows patients to enter debates and provide opinions for developing policy, standards, or research; in such cases the role of the patient is representative. The 'representative' sought here is not a statistical measure of people being studied, but a role; that of a spokesperson with relevant expertise and skills to contribute on behalf of their peers. These contributions are made directly, alongside those from health professionals and researchers, without an intermediary, but possibly with a facilitator who has the skills to interact with all the people and perspectives involved. ${ }^{5}$

Increasingly, different methods of involvement are combined to learn from a range of experiences. The passive involvement of service users, talking about their personal experiences, has been complemented by the active involvement of others well networked with their peers through service-user organisations at the various stages of the development of evidence-informed guidelines, ${ }^{6}$ developing resources to support the implementation of guidelines, ${ }^{7}$ and, in this issue of the $B J G P,{ }^{8}$ developing quality criteria to monitor the implementation of guidelines.

The area of gastrointestinal disorders an important subject for general practice - has an impressive history of public involvement. Patient groups are already actively setting research agendas, ${ }^{9}$ commissioning research, ${ }^{10}$ and developing clinical guidelines. ${ }^{11}$ Clinicians, researchers, and leaders of patient organisations co-authored a report in this issue, ${ }^{8}$ which describes involvement of these groups in implementing evidenceinformed guidelines - the last step in the research to practice pathway. Jones et al read about patients' experiences expressed in focus groups, and they read recommendations from clinical guidelines developed by gastroenterological bodies, by guideline development groups and by 
charities supporting research and patient information. Using a formal consensus development process, Jones et al drew on this material to develop quality criteria for the management of four gastrointestinal disorders.

This exemplar of public involvement was able to draw on the expertise of both individual patients and patient-led groups: groups with large nationwide memberships that elect Trustees, some of whom personally suffer with gastrointestinal disorders. The work distinguished the passive involvement of patients talking about their own lives from the active involvement of spokespeople engaging directly with evidence-informed guidelines and debating directly with clinicians and researchers. That debate may have been informed by a formal appraisal of how the guidelines were developed, taking into account the quality of research evidence and the quality of public involvement. ${ }^{12}$

The involvement of individual patients and patient groups in this work was complemented by the involvement of general practices. Less clear is the extent of the role of industry. Although not engaged in this process, industry has a key role in developing and evaluating medicines and nutritional products for managing these conditions, and a formal role in the development of NICE guidelines. The potential for indirect influence through sponsoring clinical researchers or patient groups is more difficult to assess.

Particularly valuable for this work were the formal consensus development methods which allowed time for thought and debate among the mixed group of participants. Their collective achievement has contributed to a computerised decision support system based on the quality criteria installed for piloting in 39 GP practices. The aim is to make a real difference to how patients cope and, with the support of their GPs, manage these conditions. More may yet be learned about the different perspectives on management of chronic conditions by considering what was not prioritised, and where there was no consensus.

General practice can advance by incorporating the strategies modelled here: engaging clinicians and patients directly with each other and with research evidence about health conditions and their management. Such initiatives can use and generate knowledge about implementing research findings and the growing evidence about public involvement.

Because clinical need should not be determined by the loudest voices, ${ }^{4}$ there is a need to seek individuals alongside organisations both when debating health services and research generally and for specific conditions. Finally, a healthy scepticism about consensus could prompt more detailed analysis of contributions and influence (direct and indirect) from each quarter to increase our understanding of different perspectives and collective decision-making.

\section{Sandy Oliver,}

Professor of Public Policy, Institute of Education, Social Science Research Unit, London, UK.

\section{Provenance}

Commissioned; peer reviewed.

\section{REFERENCES}

1. Sackett DL, Rosenberg WM, Gray JA, et al. Evidence based medicine: what it is and what it isn't. BMJ 1996; 312(7023): 71-72.

2. Muir Gray JA. Evidence-based healthcare: how to make health policy and management decisions. 2nd edn. London: Churchill Livingstone, 2001.

3. Oliver S, Entwistle V, Hodnett E. Roles for lay people in the implementation of health care research. In: Haines A, Donald A (eds). Getting research findings into practice. 2nd edn. London; BMJ Publishing Group 2001, 86-94.

4. National Institute for Clinical Excellence's Citizens Council. Report of the first meeting of the NICE Citizens Council. Determining 'clinical need'. Salford: NICE Citizens Council.

5. Collins HM, Evans R. The third wave of science studies: studies of expertise and experience. Soc Stud Sci 2002; 32(2): 235-296.

6. Renfrew MJ, Dyson L, Herbert G, et al. Developing evidence-based recommendations in public health incorporating the views of practitioners, service users and user representatives. Health Expect 2008; 11(1): 3-15.

7. Stewart R, Hargreaves K, Oliver S. Evidence informed policy making for health communication. Health Educ J 2005; 64(2): 120-128

8. Jones R, Hunt C, Stevens R, et al. Management of common gastrointestinal disorders: quality criteria based on patients' views and practice guidelines. $\mathrm{Br} J$ Gen Pract 2009; 59(563): 415-421.

9. Oliver S. Patient involvement in setting research agendas. Eur J Gasteroenterol Hepatol 2006; 18(9): 935-938.

10. The National Association for Colitis and Crohn's Disease (NACC). Unravelling the mystery of Inflammatory Bowel Disease. St Albans: NACC Research Awards 2002-2006.

http://www.nacc.org.uk/downloads/research/NACC_Re searchReview2001-2006.pdf (accessed 28 Feb 2009).

11. National Institute of Health and Clinical Excellence.

Irritable bowel syndrome in adults: diagnosis and management of irritable bowel syndrome in primary care. London: NICE, 2008.

12. AGREE Collaboration. Development and validation of an international appraisal instrument for assessing the quality of clinical practice guidelines: the AGREE project. Qual Saf Health Care 2003; 12(1): 18-23.

DOI: 10.3399/bjgp09X420897

\section{ADDRESS FOR CORRESPONDENCE}

\section{Sandy Oliver}

Institute of Education, Social Science

Research Unit, 20 Bedford Way,

London, WC1H ONR.

E-mail: S.Oliver@ioe.ac.uk 